\title{
The taxonomy of viruses should include viruses
}

\author{
Charles H. Calisher ${ }^{1}$
}

Received: 26 January 2016/ Accepted: 27 January 2016/Published online: 25 February 2016

(C) Springer-Verlag Wien 2016

\begin{abstract}
Having lost sight of its goal, the International Committee on Taxonomy of Viruses has redoubled its efforts. That goal is to arrive at a consensus regarding virus classification, i.e., proper placement of viruses in a hierarchical taxonomic scheme; not an easy task given the wide variety of recognized viruses. Rather than suggesting a continuation of the bureaucratic machinations of the past, this opinion piece is a call for insertion of common sense in sorting out the avalanche of information already, and soonto-be, accrued data. In this way information about viruses ideally would be taxonomically correct as well as useful to working virologists and journal editors, rather than being lost, minimized, or ignored.
\end{abstract}

Frederick A. Murphy, Life Member and former President of the International Committee on Taxonomy of Viruses (ICTV), once suggested to me that there are three things one should not discuss in polite company: religion, politics, and taxonomy. At first I thought he was joking, but I have come to realize he was not.

I am sure we can all agree that not all opinions have equal value, but we probably also can agree that all opinions are welcome, except in political areas, where no opinions are welcome. My personal opinions on the subject

C. H. Calisher: Life Member, ICTV.

Charles H. Calisher

calisher@cybersafe.net

1 Professor Emeritus, Arthropod-Borne and Infectious Diseases Laboratory, Department of Microbiology, Immunology and Pathology, College of Veterinary Medicine and Biomedical Sciences, Colorado State University, Fort Collins, CO 80523-1690, USA of viral taxonomy, while shared by some, certainly are not shared by all, unfortunate but understandable. I, for one, find taxonomy a bit boring but unquestionably necessary. "Everything in its place and a place for everything", suggested to me long ago by a teacher of mine, seems still to be a good idea. I am afraid I have taken that to heart.

The ICTV of the Virology Division of the International Union of Microbiology Societies was established in 1966 as the International Committee on Nomenclature of Viruses [1]. Consensus on virus classification (where to place viruses in hierarchical taxa, such as families, genera, and species) and naming of taxa has been a goal of viral taxonomists, an ideal goal if not a realistic one. For serious viral taxonomists, as for all serious taxonomists, the important thing is to be certain the word being used for a taxon or for a virus is the correct word (Carl von Linné (1758): Nomina si nescis, perit cognitio rerum. ["With name ignorance, knowledge perishes."]), not a close approximation of the correct word but precisely the correct word. That seems to be easier said than done, as most people do not understand the difference between "taxon" and "virus".

At first, virus taxonomy was intended to refer to taxa and the names of those taxa, and to type species for viruses and their names. Naming viruses, on the other hand, was predominantly entrusted to the people who discovered them and, as today, strain designations were not considered. Once it was decided to prepare a list of "descriptors", the individual characteristics of viruses, it took a decade for some individuals and eventually for ICTV to apply them virosphere-wide, and this enormous system eventually was to be made available via the internet and up-dated continually. Taxonomists became involved in enumerating the characteristics of viruses, because virus species are defined by properties of the very viruses that are members of the 
species. Whereas no single property must necessarily be present in every member of a polythetic class, taxonomists cannot consider virus properties as being irrelevant. The viruses that a species taxon refers to are the concrete objects that satisfy the membership conditions of the species class, whereas taxa are merely names on a list of names; as do other taxonomic specialists, most virologists simply ignore this fact and treat taxa as viruses. However, taxa are imagined, intangible, abstract, nonconcrete, hypothetical, philosophical, and essentially mystical representatives of the ideal. Taxa cannot be isolated from anything because nothing contains them. They cannot reassort. They have no genes. Nonetheless, having the nucleic acid sequence (motif) of a genome clearly is sufficient to allow plausible taxonomic placement. Alternatively, viruses are real ("concrete entities"), possessing characteristics that species do not: they are able to replicate, can infect cells, be frozen, be sold, be used by a terrorist, be dropped by an unwitting bat, and be examined by electron microscopy. That some virologists and editors do not understand the difference between a real object and a hypothetical one is quite remarkable and should be embarrassing to them.

Few things in this world seem less important and more contentious than taxonomy. I, for one, do not understand the reasons for this but it may be that people do not take the time to understand what they are talking about. No one would be so careless with a spouse, a bank account, a gambling game, the purchase of a car, or a host of other day-to-day activities, so why do people not read what they themselves have said in papers, chapters and books and why do editors let slide taxonomic nonsense? It may be that they have mimicked the poor behavior of others who did the same and survived.

As one example of the existing confusion, even the most recent version of Virus Taxonomy, Classification and Nomenclature of Viruses [3] perpetuates errors published in previous editions. On page 698 (family Rhabdoviridae) it is stated: "The genus [Lyssavirus] was at first divided into four serotypes ...". One cannot divide a genus into serotypes because genera are ideals (taxa) and serotypes are objects (tangible).

Little would be gained here by pointing out more trivial errors and typographical errors, when the larger problem is a lack of uniformity and conceptual errors in these books. They are intended to be produced each few years by the ICTV, and to list the viral orders, families, genera, species, and viruses placed in those species at a given time; taxonomy is a process. The sections were written by expert members of ICTV Study Groups, with oversight by others and final input provided by the editors of the book. Errors are corrected for subsequent editions, of course, yet few at the time of publication seem to notice them.
An optimistic effort to organize the recognized viruses of the day in a much needed computerized listing was made by ICTV. For each virus, more than two thousand pieces of data were to be recorded if available. In the end, we would have had two linked lists: one of all known viruses with their correct names and ICTV-sanctioned abbreviations, and one with all the taxa in which these viruses are classified, as well as the correct names of these taxa. With difficulty, that could have been done by more than two thousand people, if two thousand people could be found who had the knowledge and time to do it. Of course, asking people to volunteer their time and expertise would also have to have been done, or funds conjured up to pay them or their surrogates. None of that was completely successful, although some heroic individuals conscientiously and correctly completed their assigned tasks. Ian Lipkin, at Columbia University, somehow raised funds to support my efforts to put on-line a useable database of virus descriptions. Creating such a data base was beginning to look doable until we ran into problems such as various ICTV Study Group members not replying to my repeated requests for information about the viruses of their expertise, others letting me know they did not agree with the then-current definition of a virus species (irrelevant to my quest), still others indicating they serve on a Study Group for how good that would look on their C.V.s, and a few others who said, "I am supposed to do what?" My question then was "Who's in charge here?". Therefore I wrote to the thenPresident of the ICTV Executive Committee a note regarding all this, limiting my mention of individuals by name. In that note, attempting to obtain his assistance in completing my task, I used descriptive words that are inappropriate for professionals to use in public or in polite company. In response, the then-President wrote to Lipkin (with copies to me and others) that my insulting tone and language was beyond rude, that this probably was the reason I was getting so little cooperation, and suggesting that gentle advocacy, rather than coercion or scorn, was needed to convince people. It does not appear to me that the suggested gentle advocacy has been effective, as no list of viruses and their descriptors has been made available since I abandoned those efforts. That President has come and gone by now, yet little has changed. Virologists still do not have easy access to information about viruses.

As though that was not distasteful enough, for a long period the ICTV could not even agree on what a species is. Van Regenmortel had defined a virus species as "a polythetic class of viruses that constitutes a replicating lineage and occupies a particular ecological niche" [4]. That is, a polythetic class is defined in terms of a broad set of criteria, not all of which are necessary or sufficient. Whereas each virus member of a species taxon (the species category comprises all the species taxa) must possess a certain 
minimal number of defining characteristics, none of the features has to be found in every member of the category, similar to Ludwig Wittgenstein's concept of "family resemblances" [6]. There being no point in leaving well enough alone, others replaced the word and concept of "polythetic" with "monothetic", a monothetic class then being defined in terms of characteristics that are both necessary and sufficient to identify members of that class, the phenotypical and outdated Aristotelian definition of a class (walk, fly, swim, with blood, without blood, etc.). A definition of species was put forth to ignore van Regenmortel's use of the word "polythetic", such that the definition of species was suggested as "a monophyletic group of viruses whose properties can be distinguished from those of other species by multiple criteria". These changes have been argued at length, both informally and formally (http:// talk.ictvonline.org/discussions/ictv1/f/63/t/3930.aspx). So, ostensibly to make everyone feel warm and fuzzy, van Regenmortel then responded by replacing in his original definition "polythetic class" with the synonym "cluster class". That didn't help.

The writers of the original revision of van Regenmortel's classic definition likely erred in their understanding of "polythetic" as meaning "variable" [2], the arguments continued [5]. At the same time, phenotypic descriptions were seen as being of decreasing taxonomic importance and nucleotide sequences became increasingly significant, if not exclusively essential. The biological characteristics of viruses began to approach irrelevancy. This is a shame really, as it muddled the distinction between species (concepts) and their members (viruses with characteristics) even more, to wit, a nucleic acid genomic sequence clearly is sufficient to allow plausible taxonomic placement, yet that same sequence is a sequence (a chemical), not a virus (a biological entity). Further, it is clear by now that taxonomic placement provides a basis for understanding virus evolution (reflecting phylogeny) and that phenotypic characteristics can be used as an adjunct to but not as a substitute for genotypic characteristics. Still, relying solely on genotype has led to losses of the names of viruses that differ to only a small extent genetically but that may vary in regard to geographic distribution, epidemiologic spread, hosts, disease (or not) characteristics, sensitivity to anti-virals, and history. For example, the Ninth Report of the ICTV shows the (family Bunyaviridae, genus Orthobunyavirus) species California encephalitis virus and within it a single "strain", a.k.a. "isolate", La Crosse virus. What happened to California encephalitis virus itself, snowshoe hare virus, trivitattus virus, and many others within that species? They have disappeared. It was not the fault of the use of advanced genomic analyses that this happened, it was the fault of ICTV members who did not understand the difference between a species, a virus, a strain, and an isolate, and the subtle but critical importance of the non-sequence data.

Melding subjective descriptions of phenotypes (the outcomes) with objective descriptions of genotypes (the genetic but not entire basis for the phenotype), would be a more rational approach to describing viruses but viral taxonomists are limited to describing taxa by past agreements, unless a much needed "spring cleaning" is undertaken. More useful to working virologists and other students would be to associate a computer-generated, and therefore easily updated, virus data base. Such a resource would make available detailed information about the viruses placed in the various taxa. The published ICTV Reports earn money for the ICTV and a separate, on-line report made freely available would not. Nonetheless, to make the ICTV Reports useful as a working "catalogue", a taxonomy data base such as the List of Prokaryotic Names with Standing in Nomenclature (LPSN; bacterio.net) or Mammal Species of the World (Wilson \& Reeder, http:// vertebrates.si.edu/msw/mswcfapp/msw/index.cfm) would at least provide a convenient site for virologists to search and find the answer to their question, whatever it is. Most of the time, the questions will only be "What is my virus called?", "How do I spell it correctly?", "How should I abbreviate its name in my manuscript?", "What are the names of the species, genus, family, and order at the moment in which this virus is classified?".

Isn't it odd that discussions (primarily of names) of nonconcrete, imaginary, ideals (i.e., taxa) are the subject of so much conversation? Murphy was right. I suppose all this taxonomy business is fun for philosophers, would-be taxonomists, and those who love boredom, but for working virologists, it is a joke and they pay little or no attention to it, which still is preferable to those who actively demonstrate their ignorance by sabotaging it. Rather, many virologists leave it to copy editors to correct their errors; good luck with that.

Other than adding the names of newly recognized taxa, adding names to existing taxa, and adding more virus names, what is the ICTV's responsibility? There is no immediate prospect of further, useful development, but the Executive Committee of ICTV is once again considering ways in which virus isolate and species information in future reports could be linked to an online ICTV Report. We have come full circle but I am not convinced it will get done correctly this time either.

What we have now are hundreds of people who are wellmeaning, hard-working, knowledgeable, organized, and sophisticated who are working to continue the good work done in the past by viral taxonomists. What also is needed are people who, as well, apply common sense, so that the enormous amount of information already accrued can be taxonomically correct, useful to working virologists and 
journal editors, and available, rather than being lost. First, we could begin with teaching everyone the difference between a species and a virus. That is not too much to ask, is it? Then we could produce a realistic and useful on-line data base.

Acknowledgments I thank a few anonymous like-minded individuals for providing suggestions, insights, and a modicum of restraint. As a humorous aside, when I asked various colleagues on either side of this non-dilemma for their opinions, one responded that he agreed completely with the text but thought I was a bit obsessive about all this. Better to be correct than wrong, I say.

\section{References}

1. Carstens EB (2012) Introduction to Virus Taxonomy. In: King AMQ, Adams MJ, Carstens EB, Lefkowitz EJ (eds) Virus taxonomy-ninth report of the International Committee on Taxonomy of Viruses. Elsevier/Academic Press, London, pp 3-7

2. Gibbs A, Gibbs MJ (2006) A broader definition of the "virus species". Arch Virol 148:1645-1653

3. King AMQ, Adams MJ, Carstens EB, Lefkowitz EJ (eds) Virus taxonomy - ninth report of the International Committee on Taxonomy of Viruses. Elsevier/Academic Press, London

4. Van Regenmortel MH (1989) Applying the species concept to plant viruses. Arch Virol 104:1-17

5. van Regenmortel MHV, Ackermann $\mathrm{H}-\mathrm{W}$, Calisher $\mathrm{CH}$, Dietzgen RG, Horzinek MC, Keil GM, Mahy BWJ, Martelli GP, Murphy FA, Pringle C, Rima BK, Skern T, Vetten H-J, Weaver SC (2013) Virus species polemics: 14 senior virologists oppose a proposed change to the ICTV definition of virus species. Arch Virol 158:1115-1119

6. Wittgenstein L (2001) Philosophical investigations. Wiley-Blackwell, Hoboken 